\title{
Impact of Constructive Safety Climate on Worker's Safety
}

\author{
Bobby $^{1}$, Satnam Singh ${ }^{2}$ \\ 1,2 (Department of Mechanical Engineering, Lovely Professional University, Phagwara, Punjab, India) \\ ( ${ }^{1}$ bobbyarora92@gmail.com, ${ }^{2}$ Satnam.singh@1pu.co.in)
}

\begin{abstract}
The aim of the paper is to discover the impact of positive safety climate on worker's safety in the organization and to come across association between a variety of factors of safety climate and worker's safety. This paper reviews a number of studies to learn how a positive safety climate is connected to the safety of an association. Safety climate is a leading indicator of the state of safety in an organization at a particular point in time. Safety climate is the shared perceptions of employees about the policies, procedures and practices of an organization about safety. A constructive safety climate assist in many ways to get better the safety of an organization like by dipping the risk taking behavior of the workers, by improving safety performance of the workers, by dipping the underreporting of injuries and accidents. Constructive safety climate decreases the underreporting of the injuries and accidents which guide to the enhancement of the worker's safety because the origin causes of injuries and accidents are known. Most of the studies discovered that a constructive safety climate is related with enhanced safety of an organization which eventually reduces the risk of workplace injuries and accidents.
\end{abstract}

Keywords: Accidents, Perception, Safety climate, Safety behavior

\section{INTRODUCTION}

Safety is a key worry for organizations, as it is a reason of significant direct and indirect costs. By tradition, safety research has paying notice on recognizing individual characteristics, such as behavior qualities or attitudes, which are related with accident proneness. However most importantdisasters, such as Piper Alpha and Chernobyl, havedemonstrated the importance of work climate and management practices as contributor to system fail. In recent times there has been advancement away from safety procedures purely based on retrospective data or lagging pointers such as dead, lost time accident rates, and incidents towards supposed leading indicators such as safety audits or measurement of safety climate. Consequently, growing attention has been paid to the role of the work atmosphere and management practices as determinants of safety in the workplace (Barling, Kelloway, \& Iverson, 2003; Cox \&Cheyne, 2000; Hayes, Perander, Smecko, \& Trask, 1998; Parker, Axtell, \& Turner, 2001). The wordpsychological climate refers to individual perceptions of the work environment (L. A. James \& James, 1989). The term safetyclimate, thus, refers to individual perceptions of policies, procedures, and practices concerning to safety in the workplace. Most drastically, only those perceptions that connect individual's evaluation of workplace characteristics concerned with safety are measured to be perceptions of safety climate. Safety climate is a specific form of organizational climate, which explain individual perceptions of the importance of safety in the work environment. The term safety climate is conceptualized as employees share perceptions about how safety practices, policies, and procedures are executed and how much priority is given to the safety. It can be viewed as a snapshot of the condition of safety in an organization at a particular point in time that may change eventually.A variety of factors has been known as being important components of safety climate. These factors include: management values (e.g. management worry for employee safety), management and organizational practices (e.g. adequacy of training, provision of safety equipment, quality of safety management systems), communication, and employee participation in workplace health and safety. A variety of studies have long-established that these factors forecast safety-related outcomes, such as accidents and incidents. Zohar considered that safety climate was associated to safety situation of an organization directly; moreover examining employee's perception s of safety climate mightrecognize the areas requiring improvement in an organization. Level explain the normal perception of safety climate by group members as good or bad. Safety climate is the leading indicator of the position of safety in the organization. Safety of an organization can be assessed in a lot of ways like safety behavior of the workers, no. of accidents in a period of time, number of near misses, and number of injuries. Many studies show that safety climate directly or indirectly impact 
on the safety of an organization. The purpose of the paper is to carry out the literature review of published safety climate and how it can help to improve the safety of an organization.

\section{REVIEW PURPOSE AND METHOD}

Within our review we focused on examining peer-reviewed evidence (i.e. quantitative, qualitative, mixed method studies and review articles), that directly addressed the issue of safety climate, worker's safety in an organization, impact of safety climate on worker's safety. Evidence was excluded if it only addressed one of our primary areas of interest (i.e. it spoke only about safety, only to issues of safety climate, or only to issues of occupational health and safety or workplace safety culture). For we excluded evidence if it only discussed issues of safety climate but did not directly relate to $\mathrm{OH} \& \mathrm{~S}$ issues at the workplace. By narrowing our inclusion criteria, we were able to target evidence that focused on the safety climate and the impact of safety climate on various factors related to worker's safety. This, in turn, allowed us to eliminate extraneous evidence, for which we would need to extrapolate a potential relationship, and to develop more specific OH\&S recommendations.

A computerized search of the literature was conducted utilizing the papers available in various journals related to safety climate and safety. The keywords for the computerized search of the literature were "Safety climate ", and "safety performance". In total, 45 papers were retrieved and underwent full review by three reviewers. This included full reading of each papers and extraction of the following data into evidence tables: (i) the paper's central objective and research question(s); (ii) research design and methods; (iii) theoretical perspectives and/or assumptions: (iv) sample characteristics; (v) data collection and analysis; (vi) data interpretations; (vii) key findings and conclusions; (viii) a critical interpretation of how findings can inform our understanding of positive safety climate in relation to safety at work; (ix) factors that may intersect with positive safety climate to influence safety at work; and (x) research gaps and suggestions for future research. Data in the evidence tables were subsequently analyzed to characterize our sample of studies, and to identify key themes relevant to understanding how safety climate may influence safety at work.

\section{SUMMARY OF STUDIES SEPARATED BY ROLE OF SAFETY CLIMATE IN IMPROVING SAFETY}

3.1. Improve Safety compliance and participation of workers: -

Constructive safety climate helped to improve the safety behavior of workers. Safety compliance and safety participation are the two components of safety performance and good perception about the safety in organization among workers helped to improve the safety performance of workers. In [5], authors establish in their research that safety climate improves the safety performance of the workers through safety knowledge and safety motivation. They take safety compliance and safety participation as the mechanism of safety performance. Safety climate improve both safety compliance and safety participation of the workers through safety knowledge and motivation. A positive safety climate increases the knowledge of the worker which increases the understanding of workers about the safety procedures and rules and due to this their safety compliance is raise. Improved safety performance of the workers improve the safety of the organization because workers better follow the rules and participate in safety activities which help to create a safe work environment.

A positive safety climate has direct and indirect relationship with safety performance of the workers by giving knowledge and by motivating the workers to perform their work in safe manner. In [6], found in their research on manufacturing and mining organizations that safety climate strong and direct relationship with safety compliance and safety participation which are mechanism of safety performance. They also found that safety climate impact the safety performance of the workers through safety knowledge and safety participation. Safety knowledge effect both safety participation and safety compliance. Constructive safety climate helps to get better the safety knowledge and motivation of the workers that eventually improve safety performance of workers. 


\subsection{Accident underreporting among employees}

Accident underreporting is the reality and due to this underreporting of accidents organizations are not able to find out the root causes of the accidents. In [7], found in their study that there is underreporting of accidents among employees which is significantly related to safety climate of the organization. They found that employees who perceive their organizational safety climate to be poor are engaged in more accident underreporting. Underreporting of accidents may give organizations short term benefits like lesser worker's compensation loss rate but organizations are probable to pay seriouspenalty when it comes to extended health and safety matter of workers because of the fail to correct the root causes of the accidents. A positive safety climate decrease the underreporting of accidents and less total experienced accident

\subsection{Organizational injury rate underreporting}

Many times workers are not able to report their injuries to the management or due to lack of knowledge in management they not able to identify the reportable injuries. In [8], found in their study that there is underreporting of injuries among organizations which is significantly related to safety climate of organization. Organizations with deprived safety climate underreport injuries to a superior extent contrast to organizations with encouraging safety climate. They established that organizations with a poor safety climate unsuccessful to account over $80 \%$ of the eligible injuries to OSHA. One of the key dimensions of safety climate is the safety training and might be fewer training chances are given to safety officers and supervisors in poor safety climate organizations consequently they might have lees knowledge of what comprises a recordable injury.

\subsection{Vessel accidents in the container shipping}

Accidents are related to safety climate of an organization. Organizations with positive safety climate are involved in fewer accidentsdue to better safety performance of workers and better perception among workers about the importance given to safety by the management. In [9], empirically evaluates the influence of safety climate on vessel accidents. They define vessel accidents in terms of crew fatality and vessel failure. They found that dimensions of safety climate like job safety management safety practices and safety tanning is significantly related to crew fatality on the basis of logistic regression analysis. They also found that job safety is significantly related to vessel failure.

\subsection{Preventing risk taking at work}

Risk taking behaviors of the workers are related to safety climate. In constructive safety climate workers have better knowledge and understanding of risk and they are well informed about the consequences of risk taking behavior. In [10], proposed a model which links safety climate with risk taking behavior of workers. They found that knowledge and training mediates the relationship $b / w$ senior management obligation and worker risk taking behavior. They established that senior management can diminish the risk taking behavior of the workers by providing them appropriate training and knowledge and support supervisors to be more concerned in safety activities.

TABLE I: Key findings of some of the important studies

\begin{tabular}{|c|c|c|c|}
\hline S.No & Author & Industry & Key Findings \\
\hline 1 & A. Neal et al. & Hospital & $\begin{array}{c}\text { The effect of safety climate on safety } \\
\text { performance of workers was mediated by } \\
\text { knowledge and motivation. }\end{array}$ \\
\hline 2 & T.M. Probst et al. & Construction & $\begin{array}{c}\text { There was underreporting of injuries in } \\
\text { organizations and organizations with poor } \\
\text { safety climate had significantly higher rate of } \\
\text { underreporting as compared to organizations }\end{array}$ \\
\hline
\end{tabular}

Special Issue - AETM'16 
IOSR Journal of Mechanical and Civil Engineering (IOSR-JMCE)

e-ISSN: 2278-1684, p-ISSN: 2320-334X

\begin{tabular}{|c|c|c|c|}
\hline 3 & S. Yule, R. Flin\& A.Murdy & Power Generating company & $\begin{array}{c}\text { with constructive safety climate. } \\
\text { Senior management commitment toward safety } \\
\text { and safety climate was related to risk taking } \\
\text { behavior of workers. Knowledge and training } \\
\text { mediated this relationship. }\end{array}$ \\
\hline 4 & T.M. Probst & Manufacturing & $\begin{array}{c}\text { Constructive safety climate attenuate the } \\
\text { negative effects of job insecurity on safety } \\
\text { outcomes such as safety compliance, injuries, } \\
\text { and accidents }\end{array}$ \\
\hline 5 & J.M. Beus et al. & Manufacturing & $\begin{array}{c}\text { Injuries were more predictive of organizational } \\
\text { safety climate than safety climate was } \\
\text { predictive of injuries. As the time period over } \\
\text { which injuries were assessed was increased, the } \\
\text { safety climate-injury relationship attenuated. }\end{array}$ \\
\hline 6 & C-S. Lu, C.L. Tsai & Shipping & $\begin{array}{c}\text { Safety climate was related to vessel accidents in } \\
\text { respect of crew fatality and vessel failure }\end{array}$ \\
\hline 7 & T.M. Probst, A.X. Estrada & Multi organization & $\begin{array}{c}\text { There is underreporting of accidents among } \\
\text { employees. Under reporting was higher in } \\
\text { organizations with poor safety climate }\end{array}$ \\
\hline
\end{tabular}

3.6 Safety climate-injury relationship

In constructive safety climate, there was perception among workers that management was concerned about their well being and overall safety of the workplace. In response to this concern workers improve their behavior and show responsibility towards organization which ultimately reduces the number of injuries among workers.Researchers in [11], argued that since safety climate notify behavior-outcome expectancies, a positive safety climate, in which safe actions are motivated, is predictable to be connected with fewer injuries, while in an uncooperative climate, in which safe actions are not encouraged, is likely to engage in additional injuries. So safety behavior is mediates the association $\mathrm{b} / \mathrm{w}$ safety climate and injury.

In [12], Meta -analytically study the safety climate-injury association and they exposed that the prognostic effects of injuries on organizational safety climate (Group safety climate) are somewhat stronger than those of organizational safety climate on injuries. They also establish that span of time over which injuries were evaluated plays a noteworthy moderator role b/w organizational safety climate and injury association, with longer time span yielding weaker relationship. Their analysis also shows that perceived management commitment dimension is strongly related with future injuries.

In [13],established that organizational safety climate is linked to the rate of experienced employee injuries, such that more optimistic safety climate is related to less injury rate, So one method to cut the injury rate is by construct a more positive safety climate

\section{RESULT AND DISCUSSION}

It is normallyestablished that safety climate is a 'snapshot' of workforce perceptions about safety. A positive safety climate assisted to get better the worker's safety in an organization. A positive safety climate facilitated to develop the safety behavior of the workers.A positive safety climate improved the safety fulfillment and safety involvement of workers which are the mechanism of safety behavior which finally reduced the danger of injuries and accidents.A positive safety climate reduced the underreporting of injuries and accidents due to which it is straightforward for organizations to find out the root causes of these incidents and helps to prepare an appropriate 
solution. There are theoretical mechanisms like social exchange theory [14], and expectancy-valance theory [15], that might be accountable for the association between positive safety climate and workers behavior about safety. Social exchange theory forecast that if employees recognize that the organization is worried for their welfare, they will build up an inherentresponsibility to give in return by carrying out behaviorsthat assist the organization. [11], argued that perceptions of safety climate replicate employees' thinkingregarding the priority given to safety in the organization and inform behavior-outcome expectancies. [10],found in their study that safety climate is related to risk behavior of workers. Knowledge and training mediated the relationship between management commitment which was a safety climate dimension and risk taking behavior of workers. In [12], Meta -analytically showed that positive safety climate is related to lower workplace injuries.

\section{CONCLUSION}

The intention of this paper was to review the earlier studies to foundaassociation between safety climate and safety in an organization. It has been analyzed that safety climate effect the safety in an organization in many ways. Safety climate affects the safety performance of workers directly or through knowledge and motivation. In organizations where a positive safety climate is present the safety compliance and safety participation of the workers in safety activities is improved due to which chances of getting injuries or accidents are decreased. Safety fulfillment and safety involvement are the mechanism of safety climate. Safety climate affects the injury and accident reportbehavior of the workers. An organization with deprived safety climate suffers the underreporting of accidents and injuries. Due to the underreporting of the accidents organizations are not able to find out root causes of accidents to take the preventive actions. Safety climate is related to rate of injuries in an organization. In [11], found that safety climate informs behavior-outcome expectancies, a constructive safety climate, in which safe actions are encouraged, is likely to be related with a lesser amount of injuries, whereas in an negative climate, in which safe behavior is not encouraged, is expected to engage in more injuries. [16], [17], [18], found in their studies that positive safety climate is associated with fewer injuries. In [19], found that a positive safety climate reduces the negative impacts of job insecurity on the performance of workers. A strong safety climate in an organization reduces the risk taking behavior of the workers.

\section{REFERENCES}

[1] Barling, J., Loughlin, C., \&Kelloway, K. E. 2002.Development and test of a model linking safety-specific transformational leadership and occupational safety. Journal of Applied Psychology, 87, 488-496

[2] Cox, S. J., \&Cheyne, A. J. T. (2000).Assessing safety culture in offshore environments. Safety Science, 34, 1-3.

[3] Parker, S. K., Axtell, C. M., \& Turner, N. 2001.Designing a safer workplace: Importance of job autonomy, communication quality, and supportive supervisors. Journal of Occupational Health Psychology, 6, 211-228.

[4] James, L. A., \& James, L. R. (1989). Integrating work environment perceptions: Explorations into the measurement of meaning. Journal of Applied Psychology, 74, 739-751

[5] Neal, A., Griffin, M.A., Hart, P.M., 2000.The impact of organizational climate on safety climate and individual behavior. Saf. Sci. 34 (1-3), 99-109.

[6] Griffin, M.A., Neal, A., 2000. Perceptions of safety at work: a framework for linking safety climate to safety performance, knowledge, and motivation. J. Occup. Health Psychol. 5 (3), 347-358

[7] Probst, T. Estrada, E.X., 2010. Accident under-reporting among employees: testing the moderating influence of psychological safety climate and supervisor enforcement of safety practices. Accident Analysis and Prevention 42, 1438-1444.

[8] Probst, T. M., \& Estrada, A. X. (2008, April). Injury under-reporting: The moderating effects of organizational safety climate. In S. C. Payne \& J. M. Rodriguez (Chairs), Safety in organizations: Moderators and mediators ofsafety climate. Symposium conducted at the meeting of the Society for Industrial and Organizational Psychology, San Francisco, CA.

[9] Lu, C., Tsai, C., 2008.The effects of safety climate on vessel accidents in the container shipping context. Accid.Anal. Prev. 40 (2), $594-601$.

[10] Yule Steven, Flin. R, Murdy.A. 2007.Therole of management and safety climate in preventing risk taking at work. Int. J. Risk Assessment and Management (7) 137-151.

[11] Zohar, D., Luria, G., 2003. The use of supervisory practices as leverage to improve safety behavior: a cross-level intervention model. J. Saf. Res. 34 (5), 567-577

[12] Beus, Payne, Bergman, Arthur 2010. Safety climate and injuries: An examination of theoretical and Empirical relationships. Journal of applied psychology, 95, 713-727.

[13] Blau, P. M. 1964.Exchange and power in social life. New York: Wiley 
IOSR Journal of Mechanical and Civil Engineering (IOSR-JMCE)

e-ISSN: 2278-1684, p-ISSN: 2320-334X

[14] Vroom, V. H. 1959 .Some personality determinants of the effects of participation. Journal of Abnormal and Social Psychology, 59, 322327

[15] Cooper, M.D., Phillips, R.A., 2004.Exploratory analysis of the safety climate and safety behavior relationship. J. Saf. Res. 35 (5), $497-512$. Zohar, D., 2000. A group-level model of safety climate: testing the effect of group climate on micro accidents in manufacturing jobs. J. Appl. Psychol. 85 (4), 587-596.

[17] Brown, R.L., \& Holmes, H. 1986.The use of a factor analytic procedure for assessing the validity of an employee safety climate model. Accident analysis and Prevention . 18, 455-470

[18] Probst, T. M. 2004. Safety and insecurity: Exploring the moderating effect of organizational safety climate. Journal of Occupational HealthPsychology, 9, 3-10. 